\title{
Dual Energy X-ray Absorptiometry in Growth Hormone Deficiency
}

\author{
Akio Nakai, Yosuke Shigematsu, Hirokazu Tsukahara and Masakatsu Sudo
}

Department of Pediatrics, Fukui Medical School, Fukui, Japan

\begin{abstract}
Bone mineral density (BMD) of the lumbar spine was measured by dual energy X-ray absorptiometry (DXA) in nine Japanese children with growth hormone (GH) deficiency. Before hGH therapy, BMDs of the GH-deficient patients were lower than those of controls. When their bone ages were substituted for their chronological ages, however, almost all BMDs of the patients were distributed within the normal range. After 12 months of hGH therapy, the BMDs increased in 8 of $9 \mathrm{GH}$-deficient patients; they were still lower as compared to controls. The relation between BMDs and bone ages suggested delayed skeletal maturation in GH-deficient patients.
\end{abstract}

Key words: dual energy X-ray absorptiometry (DXA), growth hormone deficiency, bone mineral density (BMD), lumbar vertebrae, Japanese children

\section{Aims}

We showed in previous reports that dual energy X-ray absorptiometry (DXA) is a useful and safe method to estimate bone mineral density (BMD) in various bone diseases [1,2]. In this study, the effects of growth hormone (GH) therapy on BMD in Japanese GHdeficient patients were examined by DXA.

\section{Methods}

BMD of the lumbar vertebrae (L1-L4) was measured using a commercially available DXA unit (Hologic QDR-1000/W; Hologic

Correspondence: Akio Nakai, M.D., Department of Pediatrics, Fukui Medical School, 23 Shimoaizuki, Matsuoka, Fukui 910-11 Japan
Inc., Waltham, MA, U.S.A.). The subjects were scanned in the supine position on the scanner table. The entrance radiation dose to the subject was less than $3 \mathrm{mRem}$, which is about one-tenth of the exposure from a standard chest X-ray. The scan time for the region of interest ranged from two to seven min. Controls consisted of 49 Japanese children ( 30 boys and 19 girls), aged $0-16$ years, whose growth velocities were normal. BMDs of the GH-deficient patients ( 4 boys and 5 girls, including one with Turner syndrome) were measured before and after 12 months of hGH therapy. Their peak GH levels on more than two $\mathrm{GH}$ provocative tests were less than $10 \mathrm{ng} / \mathrm{ml}$. They received $0.5 \mathrm{IU} / \mathrm{kg}$ of $\mathrm{hGH}$ subcutaneously 5-7 times per week. Height and bone age (Greulich and Pyle) were measured. Informed consent was obtained from all of the subjects or their parents. 


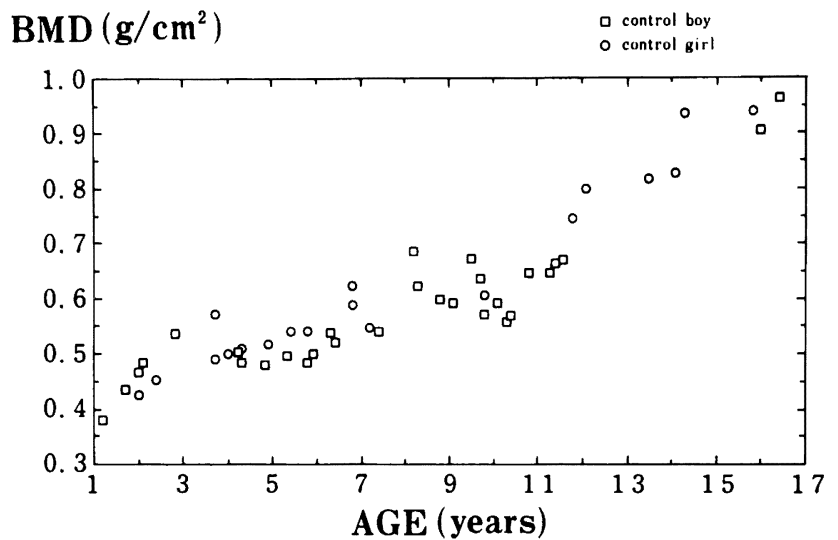

Fig 1. Lumbar vertebrae $B M D\left(\mathrm{~g} / \mathrm{cm}^{2}\right)$ versus age $(0-17$ yr) for 49 Japanese controls. Symbols $\square$ and $\bigcirc$ indicate boys and girls, respectively.

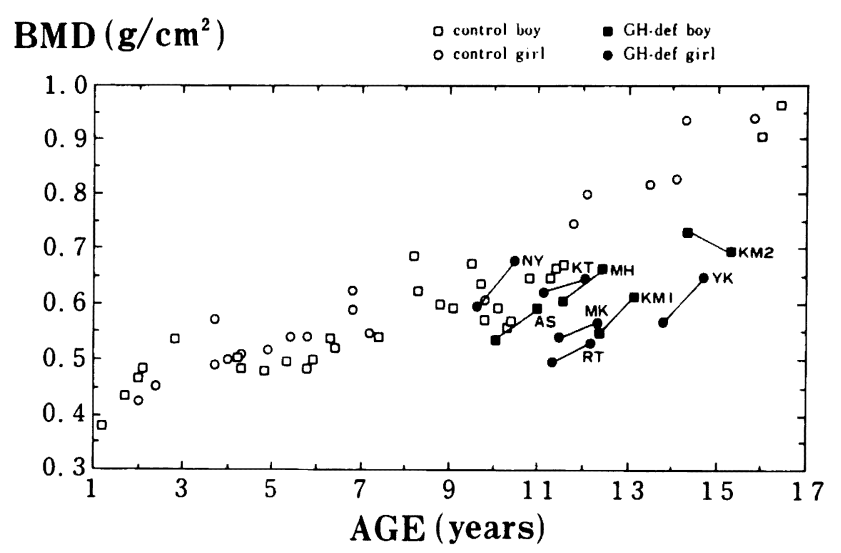

Fig 2. Lumbar vertebrae BMD for controls and GHdeficient patients, before and after 12 months of hGH therapy. Symbols and indicate GH. deficient boys and GH-deficient girls.

\section{Results}

BMDs of lumbar vertebrae of the Japanese controls were similar to those reported in a French study [3] (Fig. 1). BMDs of GH-deficient patients before hGH therapy were lower than those of the controls. After hGH therapy, the BMDs increased in 8 of 9 GH-deficient patients, but were still lower than those of the controls (Fig. 2). When their bone ages were substituted for their chronological ages, however, almost all BMDs of the patients were distributed within the

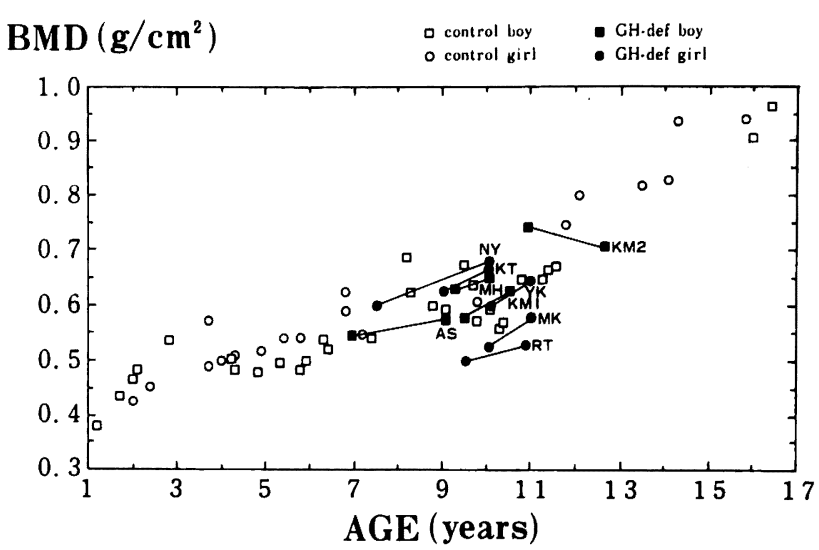

Fig 3. Lumbar vertebrae BMD for controls and GH. deficient patients, before and after 12 months of hGH therapy. Bone ages of GH-deficient patients were substituted for chronological ages.

normal range (Fig. 3). The decrease in BMD of patient KM2 might be due to an artifact. The correlations between BMD and bone age or height during hGH therapy were not significant (Fig. 4). BMDs of GH-deficient children, who had already received hGH for several years, were still lower than those of the controls (Fig. 5).

\section{Discussion and Conclusions}

We showed lower BMDs in GH-deficient patients as compared to controls. The relation between BMDs and bone ages suggested delayed skeletal maturation in GH-deficient patients. The poor correlation between BMD and bone age after one year of hGH therapy implies the presence of other factors which may cause low BMD, such as relative osteopenia, in GH deficiency.

\section{References}

1. Tsukahara H, Nakajima T, Yoshimoto M, Kuriyama M, Shigematsu Y, Hayashi S, et al. Evaluation of lumbar bone mineral density by dual energy X-ray absorptionetry. Acta Paediatr Jpn 1991; 33: 459 . 66. 


\section{DXA in GH Deficiency}
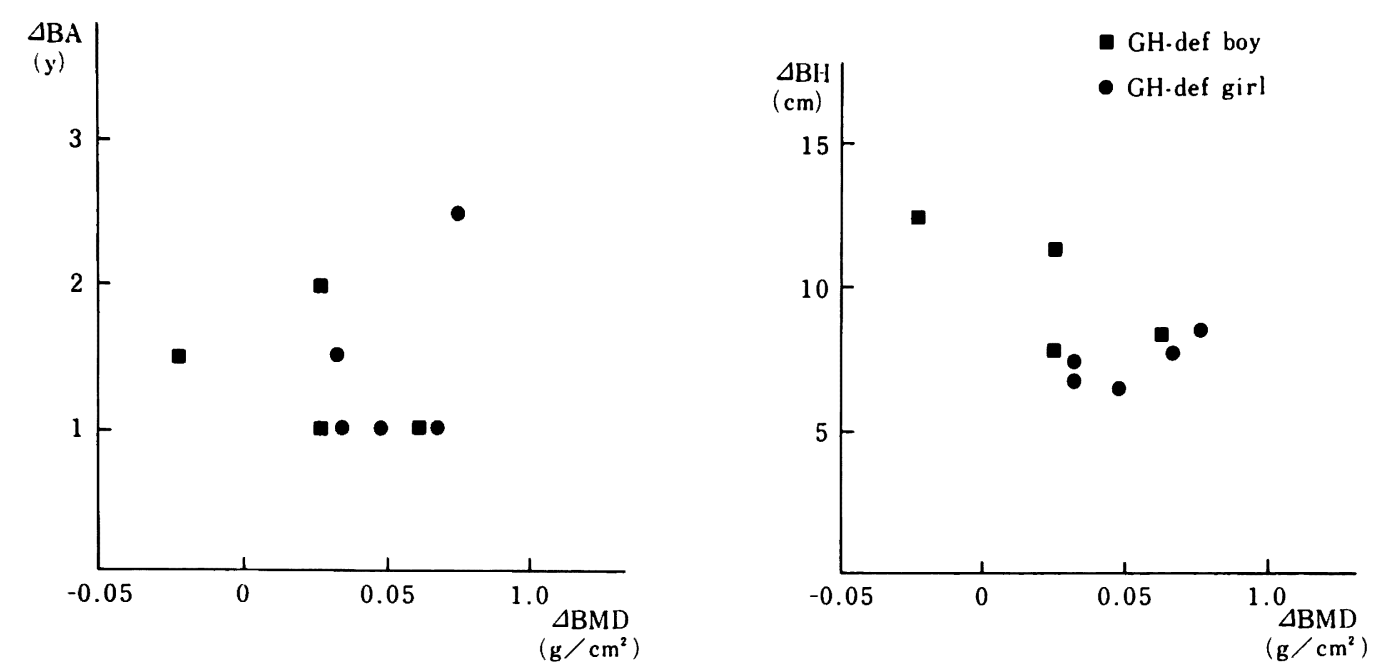

Fig 4. The relations between (A) $\triangle \mathrm{BMD}$ and $\Delta$ bone age(BA), (B) $\Delta$ BMD and $\Delta$ body height(BH).

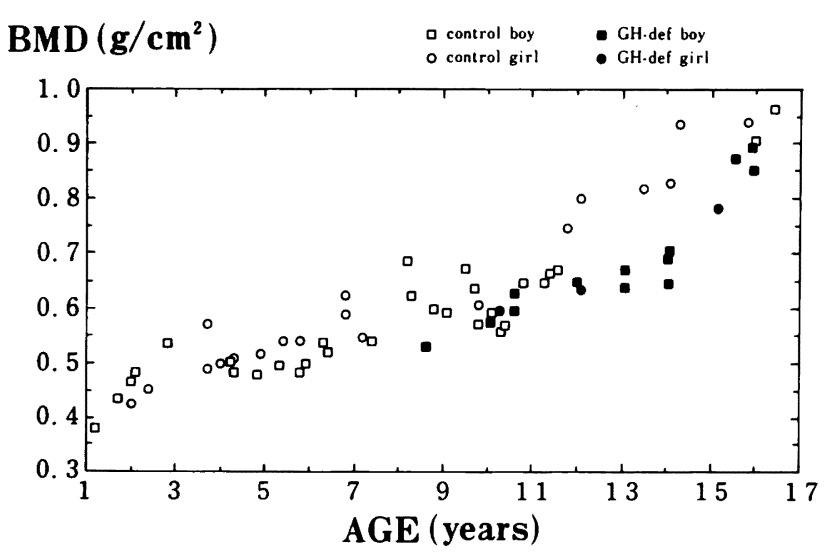

Fig 5. Lumbar vertebrae BMD for controls and GHdeficient patients, who had received hGH for several years.
2. Tsukahara H, Sudo M, Nakajima T, Fujii Y, Yamamoto K, Ishii Y. Lumbar vertebral bone mineral density in Japanese infants and children: Measurement with dualenergy x-ray absorptiometry. J Bone Mineral Metab 1992 (in press).

3. Gastre C, Braillon P, David L, Cochat P, Meunier PJ, Delmas PD. Measurement of bone mineral content of the lumbar spine by dual energy x-ray absorptiometry in normal children: correlations with growth parameters. J Clin Endcrinol Metab. 1990; 70: 1330-3. 